\title{
A rapid method for detecting extracellular proteinase activity in Cryptococcus neoformans and a survey of 63 isolates
}

\author{
PATRICIA RUMA-HAYNES*+, ALAN G. BROWNLEE† and TANIA C. SORRELL* \\ * Centre for Infectious Diseases and Microbiology, University of Sydney, Westmead Hospital, Westmead, \\ NSW and †CSIRO Animal Production, Prospect, NSW, Australia
}

\begin{abstract}
A rapid method to detect extracellular proteolytic activity around colonies of Cryptococcus neoformans was developed with tannic acid used to complex with residual protein in a solid medium. A survey was conducted with 32 isolates of $C$. neoformans var. gattii and 31 isolates of $C$. neoformans var. neoformans which were cultured on medium containing gelatin as the sole nitrogen source. The annulus of clearing around fungal colonies was $>1.2 \mathrm{~mm}$ in $24(77 \%)$ isolates of $C$. neoformans var. neoformans compared with only $7(22 \%)$ isolates of $C$. neoformans var. gattii. There was no difference in proteolytic activity between environmental and human clinical isolates of $C$. neoformans. However, there was a difference between the size of the annulus around animal isolates of $C$. neoformans var. neoformans and isolates of the same variety from other sources. The annuli around the 14 animal isolates were all $>1.2 \mathrm{~mm}$, while 7 (70\%) of 10 human clinical isolates and only $3(43 \%)$ of 7 environmental isolates were scored in the high proteinase range. A difference between the genetic types (as characterised by RAPD typing) of $C$. neoformans var. gattii was also evident with 17 (77\%) of 22 VG-I isolates having a small annulus compared with only $1(17 \%)$ of 6 VGII and VG-III isolates with annuli of similar size. Relatively low proteinase production by $C$. neoformans var. gattii may reduce local and systemic spread of infection in mammalian hosts.
\end{abstract}

\section{Introduction}

Cryptococcus neoformans, a pathogenic yeast-like fungus, causes pulmonary and neurological disease. There are two recognised varieties, $C$. neoformans var. neoformans, representing serotypes $\mathrm{A}$ and $\mathrm{D}$, and $C$. neoformans var. gattii, representing serotypes B and C. A recent report argues for the separation of serotype A from $C$. neoformans var. neoformans to a new variety, C. neoformans var. grubii, on the basis of phenotypic and molecular genetic differences [1]. The existing nomenclature has been retained for this report. The recognised varieties differ in ecology, epidemiology and clinical manifestation [2-5]. The likely route of infection is by inhalation of infectious propagules from the environment $[6,7]$, followed by dissemination to other organs via the blood stream. The factors responsible for tissue penetration by cryptococci have not been defined.

Received 1 Nov. 1999; accepted 7 Jan. 2000.

Corresponding author: P. Ruma-Haynes (e-mail:pruma@, prospect.anprod.csiro.au).
Virulence determinants of $C$. neoformans that have been well characterised to date primarily promote survival of the fungus in the host. For example, the polysaccharide capsule may protect against phagocytosis [8], laccase activity protects against leucocyte oxidants $[9,10]$ and calcineurin promotes survival at physiological temperatures [11]. Phospholipase (PL) activity may facilitate tissue invasion [12], but this has not been confirmed by characterisation or disruption of the PL gene in either variety of $C$. neoformans.

Proteinases are important virulence determinants in bacteria. By compromising host defences, causing tissue damage or increasing vasodilatation, they may provide nutrients for the pathogen and aid in its dissemination [13, 14]. Amongst the fungi, Candida albicans has nine isoforms of secreted aspartyl proteinase (SAP). Each of these is differentially expressed during the infectious process [15]. The loss of SAP1, SAP2 or SAP3 individually [16], or SAP4-SAP6 together [17], results in loss of virulence. Proteinases produced by species of Aspergillus are poorly defined as virulence factors. Although variation in the 
elastinolytic activity of $A$. fumigatus affects its virulence $[18,19]$, disruption of any or all of the known extracellular proteinases does not result in loss in virulence [20-22].

Extracellular proteinase activity in C. neoformans was first reported in 1972 [23]. Cryptococcal proteinases degrade several host proteins such as elastin, collagen, fibrin, fibrinogen, complement factors and immunoglobulins [23-25], suggesting that they may be important in tissue disruption and perturbation of host immunity. Chen et al. [25] partially characterised cryptococcal extracellular proteolytic activity in vitro as serine proteinase(s). Purification of the proteinase enzyme(s) has proved difficult, because detection of the activity requires extended periods of incubation in the substrate $[25,26]$.

Tannic acid is a relatively non-toxic substance that forms an insoluble complex with proteins. It has been used to detect proteins in polyacrylamide gels [27] and in tissue samples after counter-staining with an iron compound [28]. It has also been used to complex proteins in solid media to assess proteinases that remain functional in the presence of tannin [29]. However, some proteinases are destroyed by tannin or are unable to hydrolyse proteins complexed with tannin.

This study compared the use of tannic acid to detect extracellular proteinase activity of $C$. neoformans on solid media with other methods. A survey of $63 C$. neoformans isolates from environmental and clinical sources was performed to determine the variation in proteinase production by isolates from different sources. A recent survey of proteinase production by this pathogen has been published; however, it only examined proteinases of $C$. neoformans var. neoformans [30].

\section{Materials and methods}

\section{C. neoformans isolates and culture conditions}

Isolates of $C$. neoformans were obtained from environmental and clinical (human and animal) sources and were representative of different genetic types as assessed by a randomly amplified polymorphic DNA (RAPD) method [31-34]. Isolates were cultured from stock and maintained on Sabouraud-2\% Dextrose Agar (SAB; Difco).

\section{Proteinase assay}

Isolates were cultured on defined medium containing (/L): $\quad \mathrm{KH}_{2} \mathrm{PO}_{4} \quad 1.0 \mathrm{~g}, \quad \mathrm{MgSO}_{4} \quad 0.5 \mathrm{~g}, \quad \mathrm{NaCl} \quad 0.1 \mathrm{~g}$, $\mathrm{CaCl}_{2} .2 \mathrm{H}_{2} \mathrm{O} 0.1 \mathrm{~g}, \mathrm{MnSO}_{4} .4 \mathrm{H}_{2} \mathrm{O} 0.4 \mathrm{mg}$, thiamine. $\mathrm{HCl}$ $0.4 \mathrm{mg}, \mathrm{FeCl}_{3} 0.2 \mathrm{mg}, \mathrm{Na}_{2} \mathrm{MoO}_{4} 0.2 \mathrm{mg}$. The $\mathrm{pH}$ was adjusted to 5.5 with $\mathrm{NaOH}$ and Bacto Agar $12 \mathrm{~g}$ was added. Approximately $20 \mathrm{ml}$ were poured into $90-\mathrm{mm}$ petri dishes and allowed to set. Defined medium containing a nitrogen source $-10 \mathrm{mM} \mathrm{NH}_{4} \mathrm{Cl}$ or skim milk powder (SMP) $0.5-1.0 \% \mathrm{w} / \mathrm{v}$ or gelatin bloom 75 (Sigma) $1.0 \% \mathrm{w} / \mathrm{v}$ or bovine serum albumin (BSA; Sigma) $0.5-1.0 \% \mathrm{w} / \mathrm{v}$ - and a carbon source (galactose, fructose or xylose $1.0 \% \mathrm{w} / \mathrm{v}$, or glucose $0.5-$ $1.0 \% \mathrm{w} / \mathrm{v}$ ) was prepared and c. $5 \mathrm{ml}$ were poured on to the base layer of defined medium. Plates were incubated at $30^{\circ} \mathrm{C}$ in humid conditions, to reduce desiccation, for $2-14$ days.

Plates containing gelatin and inoculated with different strains of $C$. neoformans were assessed after 14 days. Residual protein was fixed by flooding the plate with $c$. $5 \mathrm{ml}$ of one of the following agents: $\mathrm{HgCl}_{2} \quad 5-$ $10 \% \mathrm{w} / \mathrm{v}, \mathrm{ZnCl}_{2} 5-15 \% \mathrm{w} / \mathrm{v}, \mathrm{ZnSO}_{4} 10-30 \% \mathrm{w} / \mathrm{v}$ or tannic acid (Sigma) $5-10 \% \mathrm{w} / \mathrm{v}$. The time of exposure varied with the agent used. The plates were washed thoroughly with de-ionised water. In some experiments isolates were washed off the plates with de-ionised water before fixation for observation of hydrolysis under the colony.

Plates stained with Coomassie Brilliant Blue (CBB), as described by Aoki et al. [26], were first fixed with trichloroacetic acid (TCA) $20 \% \mathrm{v} / \mathrm{v}$ for $2 \mathrm{~h}$ at room temperature. Colonies were washed off the plate with de-ionised water, as cell debris interfered with the assay. A solution of CBB $0.1 \% \mathrm{w} / \mathrm{v}$ in de-stain solution (methanol $40 \% \mathrm{v} / \mathrm{v}$, acetic acid $10 \% \mathrm{v} / \mathrm{v}$ ) was added and allowed to stand for $30 \mathrm{~min}$. The plates were washed repeatedly in de-stain solution until clearing was visible.

\section{Survey conditions}

Isolates were inoculated on to basal medium containing gelatin $1 \%$ and galactose $1 \%$ from a single colony picked from a SAB agar plate with a $1-\mu 1$ disposable loop. Plates were incubated at $30^{\circ} \mathrm{C}$ for 14 days in humid conditions to prevent drying. The width of the annulus (the radius of the colony subtracted from the radius of the zone of clearing) was measured. Preliminary results showed that the annulus produced by colonies of $C$. neoformans was relatively constant regardless of the colony size (data not shown). It was assumed that the size of the annulus correlated with the proteinase activity of $C$. neoformans.

\section{Statistical analysis}

The annuli around colonies were measured on two axes. Duplicate colonies were grown on different plates to limit measuring errors. The average annular size of each isolate was tallied for each population and the Mann-Whitney U test, a non-parametric test, was used for statistical analysis. A difference was determined to be significant when the $\mathrm{p}$ value was $\leqslant 0.05$. 


\section{Results and discussion}

Extracellular proteolytic activity in C. neoformans has been demonstrated in previous studies [23-26]. The present study confirmed that $C$. neoformans was able to grow on media containing protein (gelatin, casein in SMP, and BSA) as the sole nitrogen source, but only when the medium was supplemented with a carbon source. Proteinase activity was best visualised when the protein media were supplemented with a de-repressing carbon source such as fructose, xylose or galactose. In the presence of glucose, proteinase activity was not clearly visible (data not shown). This suggests that proteinase activity could be repressed in the presence of an easily assimilated carbon source.

To survey a large number of cryptococcal isolates for proteinase activity, a simple, reproducible method was developed. Previously described methods for detection of proteolytic activity on solid media included the use of an opaque substrate such as casein in SMP [35] or a 'fixative' with or without counter-staining. However, the use of an opaque substrate is relatively insensitive and does not detect low levels of protein hydrolysis in the medium. No zone of clearing was visible when SMP was used to detect protein hydrolysis by $C$. neoformans on solid media, regardless of the time of incubation, and whether SMP was present throughout the medium or only in the top layer (Table 1). This finding is consistent with the long incubation times needed in other studies to measure the proteinase activity of C. neoformans $[25,26]$.

Table 1 shows the methods used for visualising proteolytic clearing on a plate. Flooding gelatincontaining plates with trichloroacetic acid, $\mathrm{ZnCl}_{2}$ or $\mathrm{ZnSO}_{4}$ failed to reveal a zone of clearing. Precipitation of residual protein with trichloroacetic acid followed by counter-staining with CBB [26] was suitable for demonstrating proteolytic activity; however, the method

Table 1. Comparison of the agents used to visualise extracellular proteolysis around $C$. neoformans

\begin{tabular}{lll}
\hline Agent $^{*}$ & Concentration and time & Evidence of clearing \\
\hline $\mathrm{SMP}$ & $0.5-2 \%$ for $2-14$ days & None \\
$\mathrm{HgCl}_{2}$ & $5 \%$ for $2 \mathrm{~min}$ & Satisfactory \\
& $10 \%$ for $30 \mathrm{~s}$ & Good \\
$\mathrm{ZnCl}_{2}$ & $5-10 \%$ for $>15 \mathrm{~min}$ & None to poor \\
& $15 \%$ for $10 \mathrm{~min}$ & Satisfactory \\
$\mathrm{ZnSO}_{4}$ & $10-30 \%$ for $>15 \mathrm{~min}$ & None to poor \\
$\mathrm{TCA}$ & $20 \%$ for $2 \mathrm{~h}$ & None \\
$\mathrm{TCA}+\mathrm{CBB}$ & $5 \mathrm{~h}$ & Good \\
Tannic acid & $5 \%$ for $2 \mathrm{~min}$ & Satisfactory \\
& $10 \%$ for $15-20 \mathrm{~s}$ & Good \\
\hline
\end{tabular}

SMP, skim milk powder; TCA, trichloroacetic acid; CBB, Coomassie Brilliant Blue.

* All agents, except SMP, were tested on basal medium containing $1.0-2.0 \%$ gelatin.

$\dagger$ Poor, clearing evident with indistinct boundary; satisfactory, distinct boundary for some but not all isolates; good, well-defined boundary of clearing for majority of isolates. was time-consuming and was not practicable for examining a large number of isolates (Table 1). The use of $10 \% \mathrm{HgCl}_{2}$ or $10 \%$ tannic acid gave the best results with a very short exposure time (Table 1). However, $\mathrm{HgCl}_{2}$ has the disadvantages of toxicity to man and of killing $C$. neoformans. The use of lower concentrations $(5 \% \mathrm{w} / \mathrm{v})$ required longer exposure to produce an opaque complex, which then lacked the clarity achieved with the higher concentration. Isolates were no longer viable after exposure to $\mathrm{HgCl}_{2}$ at either concentration. Colonies of some $C$. neoformans var. neoformans isolates were detached from the surface of the medium after $\mathrm{HgCl}_{2}$ fixation, precluding measurement of the zone of clearing.

In contrast, tannic acid is relatively non-toxic [36] and produced a precipitate comparable to that of $\mathrm{HgCl}_{2}$ /protein complex. Tannic acid at $10 \%$ concentration produced an opaque complex with residual protein after 15-20 s. A longer exposure to tannic acid allowed this agent to diffuse deeper into the medium and form complexes with intact protein under the colony, thereby masking evidence of proteolysis closer to the surface. This occurred even after the surface of the medium was washed thoroughly with de-ionised water. Presumably, residual tannic acid continued to complex native gelatin in the medium. Marking the position of the zone of clearing and the colony on the base of the plate, or taking a photograph of the plate immediately after exposure to tannic acid circumvented this problem.

Cells survived after a 3-min exposure to tannic acid, which was nine times longer than that required to view a zone of clearing, and colonies did not dislodge from the surface of the medium. Therefore, this would be a useful agent to screen for mutants or variants in proteinase activity (random or otherwise) in a population without the need for replica-plating.

Thirty-one isolates of $C$. neoformans var. neoformans and 32 of $C$. neoformans var. gattii were examined for extracellular proteinase activity on medium containing gelatin, and supplemented with galactose (Table 2). All except one isolate of each variety of $C$. neoformans had measurable proteinase activity, and were included in the statistical analysis of the annular size. Neither of the remaining two isolates showed clearing around or beneath the colonies. However, their ability to grow on medium containing protein as the sole nitrogen source suggests that some activity was present, possibly associated with the cryptococcal cell wall.

There did not appear to be a difference in the size of the annulus between environmental isolates and human clinical isolates of either variety of $C$. neoformans. This finding is supported by a recent report [30] which describes the proteinase activity of 40 strains of $C$. neoformans var. neoformans from clinical (AIDS patients) and environmental (avian guano) sources. In 
Table 2. Distribution of isolates in relation to the size of the annulus produced on medium containing gelatin

\begin{tabular}{|c|c|c|c|c|}
\hline \multirow[b]{2}{*}{ Variety and source } & \multicolumn{4}{|c|}{ Size of the annulus } \\
\hline & no clearing* & small $(\leqslant 0.6 \mathrm{~mm})$ & intermediate $(0.6-1.2 \mathrm{~mm})$ & large $(>1.2 \mathrm{~mm})$ \\
\hline \multicolumn{5}{|c|}{ C. neoformans var. gattii } \\
\hline Human clinical & 1 VG-I & 6 VG-I; 1 VG-II & 1 VG-III & 2 VG-I; 1 VG-III; 2 NT \\
\hline Animal & None & 4 VG-I; 1 NT & 2 VG-I; 2 VG-II & None \\
\hline Environmental & None & 6 VG-I & $1 \mathrm{NT}$ & 1 VG-I; 1 VG-III \\
\hline Total & 1 & 18 & 6 & 7 \\
\hline \multicolumn{5}{|c|}{ C. neoformans var. neoformans } \\
\hline Human clinical & None & $1 \mathrm{VN}-\mathrm{Ia}$ & $1 \mathrm{VN}-\mathrm{Ia} ; 1 \mathrm{NT}$ & 2 VN-Ia; 1 VN-II; 4 NT \\
\hline Animal & None & None & None & $14 \mathrm{NT}$ \\
\hline Environmental & $1 \mathrm{NT}$ & $1 \mathrm{NT}$ & $2 \mathrm{NT}$ & $3 \mathrm{NT}$ \\
\hline Total & 1 & 2 & 4 & 24 \\
\hline
\end{tabular}

NT, not typed; VG, variety gattii RAPD type; VN, variety neoformans RAPD type.

* No clearing around or beneath the colony.

the present study, annuli around colonies of $C$. neoformans var. neoformans were significantly larger than those around $C$. neoformans var. gattii. The median annular size around isolates of $C$. neoformans var. neoformans was $1.6 \mathrm{~mm}$, compared with $0.4 \mathrm{~mm}$ around isolates of $C$. neoformans var. gattii $(\mathrm{p}<0.00001)$ (Fig. 1). With this as a guide, the data were divided into three categories: those with small, intermediate and large annuli (Table 2). It could be seen then that $77 \%$ (24 of 31) of C. neoformans var. neoformans isolates had an annulus $>1.2 \mathrm{~mm}$, while the majority of isolates (19 of 32) of C. neoformans var. gattii had an annular size $<0.6 \mathrm{~mm}$ (Table 2 ). This

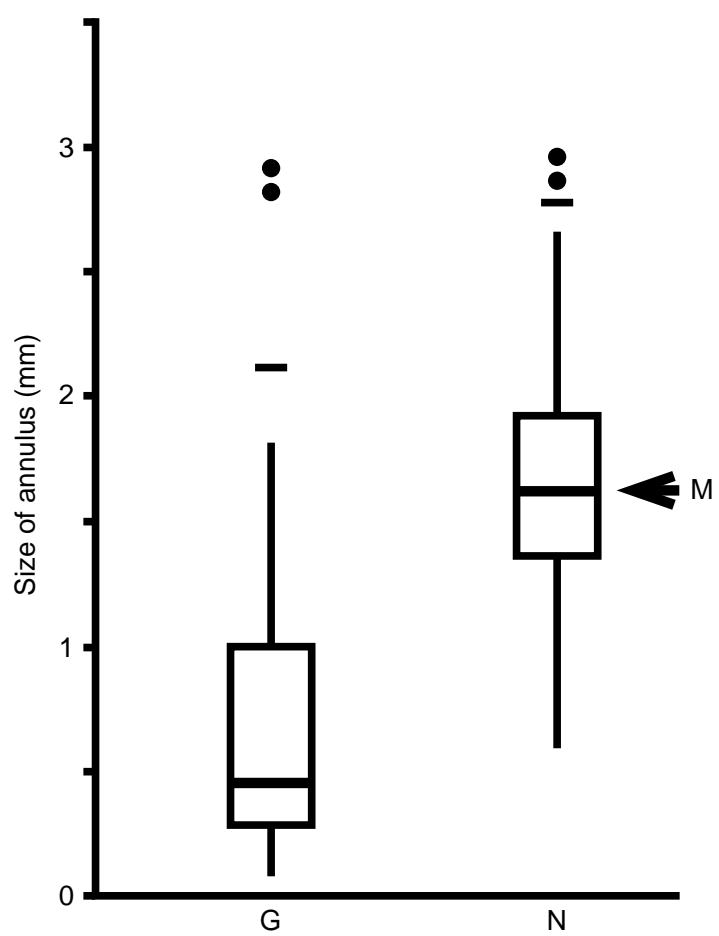

Fig. 1. Box plot of the distribution of $C$. neoformans isolates according to the size of the annulus of each isolate. The box represents the first and third quartile either side of the median, with vertical bars representing the interquartile range. $\mathrm{G}$, variety gattii $(\mathrm{n}=31)$; $\mathrm{N}$, variety neoformans $(\mathrm{n}=30)$; M, median; $\mathbf{0}$, outlier; boundary to interquartile range. may reflect a difference in the way these varieties initiate infection and disseminate. C. neoformans var. gattii produces circumscribed lesions (cryptococcomas) more commonly than $C$. neoformans var. neoformans [2]. A deficiency in proteinase production may limit the ability of $C$. neoformans var. gattii to disseminate locally and into the circulation.

Within C. neoformans var. gattii, a comparison of the genetic types revealed a difference in proteinase production. The common Australian type VG-I produced a smaller annulus than the other types (VG-II and VG-III), which are mostly found outside Australia [34]. Seventeen (77\%) of 22 isolates of VG-I produced annuli of $\leqslant 0.6 \mathrm{~mm}$ compared with $17 \%$ (1 of 6 ) of VG-II and VG-III $(\mathrm{p}<0.02)$. Few examples of the latter types were available at the time of testing, so it is not clear whether this difference in activity between the types suggests a difference in virulence or reflects a small sample size.

Differences were also found within $C$. neoformans var. neoformans depending on the source of isolation, with larger annuli around colonies of animal isolates (Table 2). All 14 animal isolates produced large annuli $(>1.2 \mathrm{~mm}$ ) compared with 43\% (3 of 7) of environmental isolates $(\mathrm{p}<0.0005)$ and $70 \%$ (7 of 10) of human clinical isolates $(\mathrm{p}<0.01)$ of $C$. neoformans var. neoformans. This may be related to differences in genetic types. It has been shown previously that the source of the strain may be related to genetic type, as patients with AIDS and other immunosuppressive conditions were more commonly infected with $C$. neoformans var. neoformans RAPD type VN-Ia [32]. An alternative explanation may be that there is a difference in the selection pressure for survival between isolates from different sources.

In summary, a rapid method to assess extracellular proteinase activity of $C$. neoformans on solid media has been developed. This method, using tannic acid, reduces the processing time from several hours [26] to a few minutes, and it is better suited for examining a 
large number of isolates. Significant differences in the size of the annulus produced by each variety may relate to differences in the type, amount or diffusibility of the proteinase(s) produced, and these may influence disease development.

\section{References}

1. Franzot SP, Salkin IF, Casadevall A. Cryptococcus neoformans var. grubii: separate varietal status for Cryptococcus neoformans serotype A isolates. J Clin Microbiol 1999; 37: 838-840.

2. Mitchell DH, Sorrell TC, Allworth AM et al. Cryptococcal disease of the CNS in immunocompetent hosts: influence of cryptococcal variety on clinical manifestations and outcome. Clin Infect Dis 1995; 20: 611-616.

3. Speed B, Dunt D. Clinical and host differences between infections with the two varieties of Cryptococcus neoformans. Clin Infect Dis 1995; 21: 28-34.

4. Ellis DH, Pfeiffer TJ. Natural habitat of Cryptococcus neoformans var. gattii. J Clin Microbiol 1990; 28: 1642-1644.

5. Staib F, Heissenhuber M. Cryptococcus neoformans in bird droppings: a hygenic-epidemiological challenge. AIDS Forschung 1989; 4: 649-655.

6. Ellis DH, Pfeiffer TJ. Ecology, life cycle, and infectious propagule of Cryptococcus neoformans. Lancet 1990; 336: 923-925.

7. Sukroongreung S, Kitiniyom K, Nilakul C, Tantimavanich S. Pathogenicity of basidiospores of Filobasidiella neoformans var. neoformans. Med Mycol 1998; 36: 419-424.

8. Kozel TR, Pfrommer GST, Guerlain AS, Highison BA, Highison GJ. Role of the capsule in phagocytosis of Cryptococcus neoformans. Rev Infect Dis 1988; 10 Suppl 2: S436-S439.

9. Jacobson ES, Emery HS. Catecholamine uptake, melanization, and oxygen toxicity in Cryptococcus neoformans. J Bacteriol 1991; 173: 401-403.

10. Salas SD, Bennett JE, Kwon-Chung KJ, Perfect JR, Williamson PR. Effect of the Laccase gene, CNLAC1, on virulence of Cryptococcus neoformans. J Exp Med 1996; 184: 377-386.

11. Odom A, Muir S, Lim E, Toffaletti DL, Perfect J, Heitman J. Calcineurin is required for virulence of Cryptococcus neoformans. EMBO J 1997; 16: 2576-2589.

12. Chen SCA, Muller M, Zhou JZ, Wright LC, Sorrell TC. Phospholipase activity in Cryptococcus neoformans: a new virulence factor? J Infect Dis 1997; 175: 414-420.

13. Travis J, Potempa J, Maeda H. Are bacterial proteinases pathogenic factors? Trends Microbiol 1995; 3: 405-407.

14. Miyoshi S, Shinoda S. Bacterial metalloprotease as the toxic factor in infection. J Toxicol Toxin Rev 1997; 16: 177-194.

15. Hube B, Monod M, Schofield DA, Brown AJP, Gow NAR. Expression of seven members of the gene family encoding secretory aspartyl proteinases in Candida albicans. Mol Microbiol 1994; 14: 87-99.

16. Hube B, Sanglard D, Odds FC et al. Disruption of each of the secreted aspartyl proteinase genes SAP1, SAP2, and SAP3 of Candida albicans attenuates virulence. Infect Immun 1997; 65: 3529-3538.

17. Sanglard D, Hube B, Monod M, Odds FC, Gow NAR. A triple deletion of the secreted aspartyl proteinase genes SAP4, SAP5, and SAP6 of Candida albicans causes attenuated virulence. Infect Immun 1997; 65: 3539-3546.

18. Kolattukudy PE, Lee JD, Rogers LM et al. Evidence for possible involvement of an elastolytic serine protease in aspergillosis. Infect Immun 1993; 61: 2357-2368.

19. Kothary MH, Chase T, Macmillan JD. Correlation of elastase production by some strains of Aspergillus fumigatus with ability to cause pulmonary invasive aspergillosis in mice. Infect Immun 1984; 43: 320-325.

20. Reichard U, Monod M, Odds F, Ruchel R. Virulence of an aspergillopepsin-deficient mutant of Aspergillus fumigatus and evidence for another aspartic proteinase linked to the fungal cell wall. J Med Vet Mycol 1997; 35: 189-196.

21. Tang CM, Cohen J, Krausz T, Van Noorden S, Holden DW. The alkaline protease of Aspergillus fumigatus is not a virulence determinant in two murine models of invasive pulmonary aspergillosis. Infect Immun 1993; 61: 1650-1656.

22. Monod M, Paris S, Sarfati J, Jaton-Ogay K, Ave P, Latgé JP. Virulence of alkaline protease-deficient mutants of Aspergillus fumigatus. FEMS Microbiol Lett 1993; 106: 39-46.

23. Muller HE, Sethi KK. Proteolytic activity of Cryptococcus neoformans against human plasma proteins. Med Microbiol Immunol 1972; 158: 129-134.

24. Brueske CH. Proteolytic activity of a clinical isolate of Cryptococcus neoformans. J Clin Microbiol 1986; 23: $631-633$.

25. Chen LC, Blank ES, Casadevall A. Extracellular proteinase activity of Cryptococcus neoformans. Clin Diagn Lab Immunol 1996; 3: $570-574$.

26. Aoki S, Ito-Kuwa $\mathrm{S}$, Nakamura $\mathrm{K}$, Kato J, Ninomiya $\mathrm{K}$, Vidotto V. Extracellular proteolytic activity of Cryptococcus neoformans. Mycopathologia 1994; 128: 143-150.

27. Aoki K, Kajiwara S, Shinke R, Nishira H. Tannic acid staining and extraction of enzymes in polyacrylamide gel electrophoresis. Anal Biochem 1979; 95: 575-578.

28. Foster AS. The use of tannic acid and iron chloride for staining cell walls in meristematic tissue. Stain Technol 1934; 9: $91-92$.

29. Osawa R, Walsh TP. Visual reading method for detection of bacterial tannase. Appl Environ Microbiol 1993; 59: $1251-1252$

30. Leone R, Cabeli P, Sinicco A, Ito-Kuwa S, Aoki S, Vidotto V. Relationship between protease production and capsule size in Cryptococcus neoformans. J Mycol Méd 1999; 9: 42-44.

31. Ruma P, Chen SCA, Sorrell TC, Brownlee AG. Characterization of Cryptococcus neoformans by random DNA amplification. Lett Appl Microbiol 1996; 23: 312-316.

32. Chen SCA, Brownlee AG, Sorrell TC et al. Identification by random amplification of polymorphic DNA of a common molecular type of Cryptococcus neoformans var. neoformans in patients with AIDS or other immunosuppressive conditions. $J$ Infect Dis 1996; 173: 754-758.

33. Sorrell TC, Brownlee AG, Ruma P, Malik R, Pfeiffer TJ, Ellis DH. Natural environmental sources of Cryptococcus neoformans var. gattii. J Clin Microbiol 1996; 34: 1261-1263.

34. Sorrell TC, Chen SCA, Ruma P et al. Concordance of clinical and environmental isolates of Cryptococcus neoformans var. gattii by random amplification of polymorphic DNA analysis and PCR fingerprinting. $J$ Clin Microbiol 1996; 34: 1253-1260.

35. Gornini L, Fromageot C. Une protéinase bactérienne (Micrococcus lysodeikticus) nécessitant l'ion calcium pour son fonctionnement. [A bacterial proteinase (from M. lysodeikticus) requiring calcium ion for its functioning.] $C R$ Hebd Séances Acad Sci 1949; 229: 559-561.

36. Robinson HJ, Graessle OE. Toxicity of tannic acid J Pharmacol Exp Ther 1943; 77: 63-69. 